\title{
The Survey on Women's Health in China
}

\author{
Xiammi Wang* \\ Department of social work, China Women's University, China
}

\begin{abstract}
Objective: To explore women's health status and the factors influencing women's health in Beijing, China.

Methods: Using the data of the 3th national survey on the status of Chinese women in 2010, 1386 women in Beijing was selected as a sample. Statistical analysis was done by SPSS version 19 including Chi-square test and Multinomial Logistic regression.

Results: $62.9 \%$ of women thought they had very good general health status. $21.5 \%$ of women suffered from chronic diseases. Women with physical disability was $2.7 \%$. The prevalence rate of gynecological disease was $13.2 \% .17 .7 \%$ and $38.5 \%$ of women had experienced cesarean delivery and induced abortion respectively. The percent of pap smear and breast cancer screening was $87.8 \%$ and $88.5 \%$ among women in Beijing. Women's age had a significant association with chronic disease, gynecological disease, prenatal care, pap smear, breast screening, cesarean delivery, and induced abortion. Gender-based violence affected the rate of women's gynecological examination, prenatal care, and induced abortion.
\end{abstract}

Conclusion: Women's health status and positive health behavior should be further improved in Beijing. Effective measures could be taken from two aspects of service providers and women to meet women's personalized health needs.

\section{Introduction}

There were some achievements for women's health after 1995 World Conference on women. It has been 20 years since countries signed pledges in the 1995 Beijing Declaration and Platform of Action. However, women's health is still very much a part of the unfinished agenda. Thousands of women face severe challenges of death or disability every year from preventable diseases, such as chronic noninfectious disease. The top of them are cancer and reproductive health [1].

Two of the most common cancers affecting women's life and selfidentity are breast and cervical cancers, which might lead to breast and uterus removal. Detecting both these cancers early is key to keeping women alive and healthy. The latest global figures show that around half a million women die from cervical cancer and half a million from breast cancer each year. The vast majority of these deaths occur in low and middle-income countries where screening, prevention and treatment are almost non-existent [1].

Sexual and reproductive health problems are responsible for one third of health issues for women between the ages of 15 and 44 years. Unsafe sex is a major risk factor - particularly among women and girls in developing countries. Therefore, it is so important to get services to the 222 million women who aren't getting the contraception services they need.

Women's reproductive health are affected by unwanted pregnancy, induced abortion, maternal morbidity and mortality, reproductive cancers, and even potential or actual gender-based physical, sexual, and emotional violence. Every two minutes a woman will die of unnecessary preventable pregnancy-related complications, leaving behind impoverished children and struggling families. The health of women and girls is of particular concern because, in many societies, they are disadvantaged by discrimination rooted in sociocultural factors that prevent women and girls to benefit from quality health services and attaining the best possible level of health, such as unequal power relationship between men and women, social norms that decrease education and paid employment opportunities; and an exclusive women's reproductive roles.

The health of women impacts on the health of the family and society, and so is critical for national development. This study aimed to find out the current health situation of women in Beijing and then to explore the effective efforts to address women's unmet health needs.

\section{Methods}

The study was based on the data of the 3th national survey on the status of Chinese women. 1386 eligible women's questionnaires were selected as a sample among the 3011 questionnaires in Beijing. The inequality probability sampling method in three stages was adopted by the 3th national survey on the status of Chinese women in different areas of China. The primary sample unit was street/town. Systematic sampling was used to select randomly 27 streets and 10 towns according to the proportion of population size from all the 135 streets and 182 towns in Beijing. 2 streets and 2 towns were sampled by systematic sampling method from the 27 streets and 10 towns at the second stage. Then 15 families were chosen randomly from every sample unit among the 2 streets and 2 towns by a random starting point of equal probability systematic sampling. One person older than 15 was investigated by simple random sampling in every chosen family.

\section{Results}

There were 1386 eligible female questionnaires. Most of them were aged between $30-60$ years old. 219 (15.8\%) and $126(9.1 \%)$ women were

Correspondence to: Xiammi Wang, Department of social work, China Women's University, China, E-mail: wangxmi@163.com

Received: August 22, 2017; Accepted: September 21, 2017; Published: September 25, 2017 
younger than 30 and older than 60, respectively. 464 (33.5\%) women had received junior middle school education, with the highest ratio. 1142 women were married and $70.1 \%$ (869/1227) of them had one child. The percent of women with a job was a little higher than the women with no job. $85.4 \%(1184 / 1386)$ and $92.9 \%$ (1287/1386) of women had the social endowment insurance and social medical insurance. 173 (15.1\%) women experienced gender-based violence (Table 1).

$871(62.9 \%)$ women thought their general health status was good and $85(6.1 \%)$ women believed they were in bad health situation. 298 $\bigotimes 21.5 \%$ \women in Beijing suffered from chronic diseases, mainly including cardiovascular disease, diabetes and cancer. 38 (2.7\%) women had physical disability. The rate of gynecological disease was $13.2 \%$ (183/1386). The common gynecological problems bothered women were vaginitis, uterine fibroid and menstruation disorder. 972 (84.0\%) women had prenatal examination during their last pregnancy. But only 666 (68.5\%) women followed doctor's advice and checked regularly. 170 (17.5\%) women only had once or twice prenatal examination during the whole pregnancy. $1042(87.8 \%)$ and $1050(88.5 \%)$ women had routine screening of smear and breast cancer respectively. $205(17.7 \%)$ women were implemented cesarean delivery surgery. 527 (38.5\%) women experienced induced abortion in Beijing. And the percent of women with repeated abortion was $36.1 \%$ (190/527). The first reason (58.3\%) for women to choose induced abortion was the one-child policy forbade them to have second child if women were pregnant. 225 (16.2\%) women ever decided not to go to see a doctor in last three years when they feel bad because they thought it was not necessary or serious enough and they could not afford medical fee (Table 2).

The factors affected women's health status and behavior was analyzed by Chi-square test. The results showed that women aged 50 60 years old, with college or above education, married, one child and job thought their general health status was better than others.

Table 1. The characteristics of participants in Beijing $(\mathrm{N}=1386)$

\begin{tabular}{|c|c|c|c|}
\hline & & Frequency & Valid percent \\
\hline \multirow{5}{*}{$\begin{array}{c}\text { Age } \\
\%\end{array}$} & $<30$ & 219 & 15.8 \\
\hline & $30-40$ & 244 & 17.6 \\
\hline & $40-50$ & 352 & 25.4 \\
\hline & $50-60$ & 445 & 32.1 \\
\hline & $\geq 60$ & 126 & 9.1 \\
\hline \multirow{4}{*}{ Education level } & $\leq$ Primary school & 143 & 10.3 \\
\hline & Junior middle school & 464 & 33.5 \\
\hline & Senior high school & 401 & 28.9 \\
\hline & $\geq$ Collage & 378 & 27.3 \\
\hline \multirow{4}{*}{ Marital status } & Unmarried & 159 & 11.5 \\
\hline & Married & 1142 & 82.4 \\
\hline & Divorced & 41 & 3.0 \\
\hline & Widowed & 44 & 3.1 \\
\hline \multirow{3}{*}{$\begin{array}{l}\text { Number of children } \\
\qquad(\mathrm{N}=1227)\end{array}$} & 0 & 63 & 5.1 \\
\hline & 1 & 860 & 70.1 \\
\hline & $\geq 2$ & 304 & 24.8 \\
\hline \multirow{2}{*}{ Nation } & Han & 1300 & 93.8 \\
\hline & Minority & 86 & 6.2 \\
\hline \multirow{2}{*}{ Job } & Yes & 801 & 57.8 \\
\hline & No & 585 & 42.2 \\
\hline \multirow{2}{*}{$\begin{array}{l}\text { Social endowment } \\
\text { insurance }\end{array}$} & Yes & 202 & 14.6 \\
\hline & No & 1184 & 85.4 \\
\hline \multirow{2}{*}{$\begin{array}{l}\text { Social medical } \\
\text { insurance }\end{array}$} & Yes & 99 & 7.1 \\
\hline & No & 1287 & 92.9 \\
\hline \multirow{2}{*}{$\begin{array}{c}\text { Gender-based } \\
\text { violence } \\
(\mathrm{N}=1145)\end{array}$} & Yes & 173 & 15.1 \\
\hline & No & 972 & 84.9 \\
\hline
\end{tabular}

Table 2. Women's physical health status and health behaviour in Beijing

\begin{tabular}{|c|c|c|c|}
\hline & & Frequency & Valid percent \\
\hline Chronic disease & Yes & 298 & 21.5 \\
\hline Physical disability & Yes & 38 & 2.7 \\
\hline $\begin{array}{l}\text { Gynecological } \\
\text { disease }\end{array}$ & Yes & 183 & 13.2 \\
\hline Prenatal examination & Yes & 972 & 84.0 \\
\hline \multirow{2}{*}{$\begin{array}{l}\text { Frequency of } \\
\text { prenatal care }\end{array}$} & Irregular & 306 & 31.5 \\
\hline & Regular & 666 & 68.5 \\
\hline Screening of smear & Yes & 1042 & 87.8 \\
\hline Breast examination & Yes & 1050 & 88.5 \\
\hline \multirow{2}{*}{ Delivery mode } & Natural delivery & 951 & 82.3 \\
\hline & Cesarean delivery & 205 & 17.7 \\
\hline Induced abortion & Yes & 527 & 38.5 \\
\hline \multirow{2}{*}{$\begin{array}{c}\text { Frequency of } \\
\text { induced abortion }\end{array}$} & 1 & 337 & 63.9 \\
\hline & $\geq 2$ & 190 & 36.1 \\
\hline \multirow{5}{*}{$\begin{array}{l}\text { Reasons of induced } \\
\text { abortion }\end{array}$} & One-child policy & 307 & 58.3 \\
\hline & No willing & 168 & 31.9 \\
\hline & Health problems & 30 & 5.7 \\
\hline & Work/study stress & 12 & 2.3 \\
\hline & Others & 10 & 1.8 \\
\hline Not to see a doctor & Yes & 225 & 16.2 \\
\hline \multirow{6}{*}{$\begin{array}{c}\text { Reasons of not to see } \\
\text { a doctor }\end{array}$} & No necessary & 85 & 37.8 \\
\hline & Unaffordable & 59 & 26.3 \\
\hline & No time inconvenient & 51 & 22.7 \\
\hline & Inconvenient & 12 & 5.3 \\
\hline & $\begin{array}{l}\text { No medical } \\
\text { insurance }\end{array}$ & 6 & 2.6 \\
\hline & Others & 12 & 5.3 \\
\hline
\end{tabular}

The occurrence of chronic disease was significantly associated with women's age, education level, marital status, number of children and having job. The rate of chronic disease increased significantly after women were older than 50 . The highest rate was in the group of 5060 years old. Women with junior middle school, married and having one child were most likely suffered chronic disease. The rate was higher among women with no job compared with women with job. Perhaps because women with job had higher income, more self-worth and stronger social support than women with no job.

There was significant relationship between physical disability and women's age, marital status, nation, and job. The percent of physical disability among women older than 50 was significant higher than that of women younger than 50 . Their disability might be associated with the physical functional disorder caused by chronic disease, such as cardiovascular disease. Women married, Han and with no job had more possibility to go through physical disability.

Women's age and the experience of gender-based violence affected the incidence of gynecological disease significantly. The highest rate of gynecological disease was at 40-50 aged women in Beijing. The rate was also higher in women experienced gender-based violence compared with women no violence.

The behavior of prenatal examination in the recent fertility was significantly related to women's age, education level, marital status, number of children and gender-based violence. The rate of prenatal examination was lower in the women younger than 30 years old, with primary school or below education level, widowed, having 2 or more children, and experienced gender-based violence. The rate of cervical screening of smear was lowest in women aged younger than 30 or older than 60 , with primary school or below education. Women married and with 1 child had the highest rate of cervical screening of smear. Also, 
women married, with one child and job had highest rate of common breast cancer screening. The higher rate of induced abortion was significantly related to women aged 40-60 years, married, with one child, job and gender-based violence in Beijing (Table 3).

Multinomial Logistic regression further analyzed the influencing factors, including age, education level, marital status, number of children, nation, job and gender-based violence, to find out their relationship with women's chronic disease, physical disability, gynecological disease, prenatal care, cervical screening of smear, breast cancer screening, cesarean delivery and induced abortion. It indicated that women's age had significant relationship with the incidence of chronic disease, gynecological disease, prenatal care, cervical screening of smear, breast cancer screening, cesarean delivery and induced abortion. Women's education level and job affected their behavior of seeking breast cancer screening service significantly. The screening rate was higher among women with higher education level and job. Women experienced gender-based violence had higher incidence rate of gynecological disease and induced abortion compared with women with no violence. Marital status and nation had no significant relationship with women's health [Table 4].

\section{Discussion}

Many researches considered studies should have included $>$ or $=$ 1 measure of the following: general health; torture, abuse, sex-andgender-based violence, depression, anxiety, etc. [2]. The variables included general health, history of chronic disease, physical disability, gynecological disease, prenatal care, cervical screening of smear, breast cancer screening, cesarean delivery, induced abortion, and genderbased violence.

Chronic disease is the main health concerns for people. $298(21.5 \%, 1386)$ women in Beijing suffered from it in this study. The percentage was quite higher compared with the other studies. Chronic disease is a series of diseases, including cardiovascular and cerebrovascular diseases, malignant tumor, metabolic abnormalities, psychiatric disorder, genetic disease, chronic occupational diseases, chronic bronchitis and emphysema, etc. Chronic disease was one of the serious threat to woman's health and mortality. The investigation in Colombia found that there were 727,146 deaths due to chronic non-communicable diseases between 2008 and 2012 [3]. The top five causes of death were heart diseases, injuries due to

Table 3. The difference of health status and health behaviour with different characteristics of women in Beijing

\begin{tabular}{|c|c|c|c|c|c|c|c|c|c|c|}
\hline & & $\begin{array}{c}\text { Chronic disease } \\
\mathrm{n}=298 \\
\mathrm{n}(\%)\end{array}$ & $\begin{array}{c}\text { Physical } \\
\text { disability } \\
\mathrm{n}=38 \\
\mathrm{n}(\%)\end{array}$ & $\begin{array}{c}\text { Gynecolo-gical } \\
\text { disease } n=183 \\
n(\%)\end{array}$ & $\begin{array}{c}\text { Prenatal } \\
\text { examinati-on } \\
\mathrm{n}=972 \\
\mathrm{n}(\%)\end{array}$ & $\begin{array}{c}\text { Cervical } \\
\text { screening } \\
\mathrm{n}=1042 \\
\mathrm{n}(\%)\end{array}$ & $\begin{array}{c}\text { Breast } \\
\text { screening } \\
\mathrm{n}=1050 \\
\mathrm{n}(\%)\end{array}$ & $\begin{array}{c}\begin{array}{c}\text { Cesarean } \\
\text { delivery } \\
\mathrm{n}=205 \\
\mathrm{n}(\%)\end{array}\end{array}$ & $\begin{array}{c}\text { Induced } \\
\text { abortion } \\
\mathrm{n}=527 \mathrm{n}(\%)\end{array}$ & $\begin{array}{c}\text { Good health } \\
\text { status } \\
n=396 \mathrm{n}(\%)\end{array}$ \\
\hline \multirow{7}{*}{ Age } & $<30$ & $7(3.2)$ & $1(0.5)$ & $6(2.8)$ & 43 (93.5) & $86(61.9)$ & $103(74.1)$ & $29(63.0)$ & $11(5.2)$ & $119(54.6)$ \\
\hline & $30-40$ & $26(10.7)$ & $2(0.8)$ & 34 (13.9) & $199(95.2)$ & $199(90.0)$ & $196(88.7)$ & $78(37.3)$ & $84(35.0)$ & $89(36.5)$ \\
\hline & $40-50$ & $57(16.2)$ & $13(3.7)$ & $73(20.7)$ & $297(87.4)$ & $310(95.7)$ & $301(92.9)$ & $43(12.7)$ & $160(45.7)$ & $88(25.0)$ \\
\hline & $50-60$ & $145(32.6)$ & $16(3.6)$ & $60(13.5)$ & $343(78.3)$ & $360(89.8)$ & $363(90.5)$ & $44(10.0)$ & $210(47.5)$ & $83(18.7)$ \\
\hline & $\geq 60$ & $63(50.0)$ & $6(4.8)$ & $10(7.9)$ & $90(72.6)$ & $87(85.3)$ & $87(85.3)$ & $11(8.9)$ & $62(49.2)$ & 17 (13.6) \\
\hline & $\chi^{2}$ & 159.40 & 12.01 & 40.87 & 48.08 & 109.00 & 37.02 & 150.00 & 129.60 & 144.30 \\
\hline & $\mathrm{P}$ & 0.000 & 0.017 & 0.000 & 0.000 & 0.000 & 0.000 & 0.000 & 0.000 & 0.000 \\
\hline \multirow{6}{*}{ Education level } & $\begin{array}{c}\leq \text { Primary } \\
\text { school }\end{array}$ & $41(28.7)$ & $7(4.9)$ & $23(16.1)$ & $69(50.0)$ & $89(82.4)$ & $91(84.3)$ & $8(5.8)$ & $58(40.6)$ & $32(22.4)$ \\
\hline & Middle school & $127(27.4)$ & $14(3.0)$ & $69(14.9)$ & $371(82.1)$ & $376(90.8)$ & $360(87.0)$ & $65(14.4)$ & $209(45.4)$ & $122(26.3)$ \\
\hline & High school & 78 (19.5) & $12(3.0)$ & $53(13.2)$ & $319(91.1)$ & $317(90.6)$ & $317(90.6)$ & $75(21.5)$ & $164(41.5)$ & $109(27.2)$ \\
\hline & $\geq$ Collage & $52(13.8)$ & $5(1.3)$ & $38(10.1)$ & $213(98.2)$ & $260(82.5)$ & $282(89.5)$ & $57(26.3)$ & $96(25.8)$ & $133(35.3)$ \\
\hline & $\chi^{2}$ & 28.26 & 5.57 & 5.23 & 165.70 & 17.09 & 4.66 & 31.17 & 36.45 & 41.89 \\
\hline & $\mathrm{P}$ & 0.000 & 0.135 & 0.156 & 0.000 & 0.001 & 0.198 & 0.000 & 0.000 & 0.000 \\
\hline \multirow{6}{*}{ Marital status } & Unmarried & $5(3.1)$ & $0(0.0)$ & $3(1.9)$ & $0(0.0)$ & $39(47.6)$ & $62(75.6)$ & $0(0.0)$ & $2(1.3)$ & $92(57.9)$ \\
\hline & Married & $264(23.1)$ & $32(2.8)$ & $168(14.7)$ & $903(83.9)$ & $935(91.0)$ & $916(89.1)$ & $191(17.8)$ & $487(43.0)$ & $293(25.7)$ \\
\hline & Divorced & $11(26.8)$ & $2(4.9)$ & $7(17.1)$ & $36(97.3)$ & 34 (94.4) & $35(97.2)$ & $8(21.6)$ & $16(39.0)$ & $8(19.5)$ \\
\hline & Widowed & $18(40.9)$ & $4(9.1)$ & $5(11.4)$ & $33(75.0)$ & 34 (82.9) & $37(90.2)$ & $6(13.6)$ & $22(50.0)$ & $3(6.8)$ \\
\hline & $\chi^{2}$ & 44.02 & 11.85 & 20.05 & 7.53 & 135.70 & 16.52 & 0.89 & 100.90 & 96.50 \\
\hline & $\mathrm{P}$ & 0.000 & 0.008 & 0.000 & 0.023 & 0.000 & 0.001 & 0.641 & 0.000 & 0.000 \\
\hline \multirow{5}{*}{$\begin{array}{l}\text { Number of } \\
\text { children }\end{array}$} & 0 & $4(6.3)$ & $0(0.0)$ & $6(9.5)$ & $0(0.0)$ & $46(82.1)$ & $46(82.1)$ & $0(0.0)$ & $9(14.5)$ & $26(41.3)$ \\
\hline & 1 & $204(23.7)$ & $28(3.3)$ & $125(14.5)$ & $770(90.2)$ & $733(92.7)$ & $718(90.8)$ & $181(21.2)$ & $385(45.1)$ & $193(22.5)$ \\
\hline & $\geq 2$ & $85(28.0)$ & $10(3.3)$ & $49(16.1)$ & $202(66.7)$ & $224(86.8)$ & $224(86.8)$ & $24(7.9)$ & $131(43.4)$ & $85(28.0)$ \\
\hline & $\chi^{2}$ & 13.45 & 2.12 & 1.86 & 91.92 & 13.17 & 6.50 & 27.10 & 22.03 & 22.71 \\
\hline & $\mathrm{P}$ & 0.001 & 0.346 & 0.396 & 0.000 & 0.001 & 0.039 & 0.000 & 0.000 & 0.004 \\
\hline \multirow{4}{*}{ Nation } & Han & $285(21.9)$ & $38(2.9)$ & $174(13.4)$ & $920(84.1)$ & $978(87.7)$ & $989(88.7)$ & $192(17.6)$ & $502(39.0)$ & $369(28.4)$ \\
\hline & Minority & $13(15.1)$ & $0(0.0)$ & $9(10.6)$ & $52(82.5)$ & $64(89.9)$ & $61(84.7)$ & $13(20.6)$ & $25(29.8)$ & $27(31.4)$ \\
\hline & $\chi^{2}$ & 2.21 & 4.94 & 0.56 & 0.11 & 0.09 & 1.05 & 0.38 & 2.87 & 1.90 \\
\hline & $\mathrm{P}$ & 0.137 & 0.026 & 0.456 & 0.743 & 0.768 & 0.306 & 0.535 & 0.091 & 0.754 \\
\hline \multirow{4}{*}{ Job } & Yes & $110(13.7)$ & $16(2.0)$ & $116(14.5)$ & $531(84.3)$ & $617(88.1)$ & $631(90.1)$ & $122(19.4)$ & $270(34.3)$ & $262(32.8)$ \\
\hline & No & $188(32.1)$ & $22(3.8)$ & $67(11.5)$ & $441(83.7)$ & $425(87.3)$ & $419(86.0)$ & $83(15.7)$ & $257(44.2)$ & $134(22.9)$ \\
\hline & $\chi^{2}$ & 67.85 & 3.94 & 2.76 & 0.08 & 0.21 & 4.74 & 2.61 & 13.85 & 45.93 \\
\hline & $\mathrm{P}$ & 0.000 & 0.047 & 0.097 & 0.780 & 0.651 & 0.029 & 0.106 & 0.000 & 0.000 \\
\hline \multirow{4}{*}{ Violence } & No & $225(23.1)$ & $29(3.0)$ & $129(13.3)$ & $782(86.1)$ & $975(90.5)$ & $781(89.0)$ & $159(17.5)$ & $398(41.2)$ & $256(26.4)$ \\
\hline & Yes & $38(22.0)$ & $3(1.7)$ & $39(22.5)$ & $123(72.8)$ & $144(93.5)$ & $139(90.3)$ & $32(18.9)$ & $88(51.5)$ & $38(22.0)$ \\
\hline & $\chi^{2}$ & 0.12 & 0.84 & 10.08 & 18.90 & 1.40 & 0.23 & 0.19 & 6.20 & 5.87 \\
\hline & $\mathrm{P}$ & 0.733 & 0.358 & 0.001 & 0.000 & 0.237 & 0.630 & 0.661 & 0.013 & 0.209 \\
\hline
\end{tabular}


Table 4. Multinomial Logistic regression analysis on influencing factors of women's health status and health behaviour in Beijing

\begin{tabular}{|c|c|c|c|c|c|c|c|}
\hline & & \multirow{2}{*}{ B } & \multirow{2}{*}{$\mathbf{S E}$} & \multirow{2}{*}{$\mathbf{P}$} & \multirow{2}{*}{ OR } & \multicolumn{2}{|c|}{ OR 95\% CI } \\
\hline & & & & & & Lower bound & Upper bound \\
\hline \multicolumn{8}{|c|}{ Chronic disease } \\
\hline \multirow{4}{*}{ Age } & $<30$ & -2.886 & 0.649 & 0.000 & 17.925 & 5.022 & 63.977 \\
\hline & $30-40$ & -2.021 & 0.330 & 0.000 & 7.545 & 3.951 & 14.409 \\
\hline & $40-50$ & -1.364 & 0.273 & 0.000 & 3.912 & 2.290 & 6.684 \\
\hline & $50-60$ & -0.683 & 0.230 & 0.003 & 1.979 & 1.261 & 3.108 \\
\hline Job & Yes & -0.476 & 0.173 & 0.006 & 0.610 & 1.146 & 2.262 \\
\hline \multicolumn{8}{|c|}{ Gynecological disease } \\
\hline \multirow{4}{*}{ Age } & $<30$ & -0.724 & 0.734 & 0.324 & 0.485 & 0.115 & 2.043 \\
\hline & $30-40$ & 0.757 & 0.437 & 0.083 & 2.131 & 0.906 & 5.015 \\
\hline & $40-50$ & 1.237 & 0.407 & 0.002 & 3.445 & 1.551 & 7.652 \\
\hline & $50-60$ & 0.636 & 0.389 & 0.101 & 1.890 & 0.882 & 4.047 \\
\hline Violence & Yes & 0.636 & 0.212 & 0.003 & 1.888 & 1.247 & 2.859 \\
\hline \multicolumn{8}{|c|}{ Prenatal care } \\
\hline \multirow{4}{*}{ Age } & $<30$ & 0.904 & 0.682 & 0.185 & 2.469 & 0.649 & 9.394 \\
\hline & $30-40$ & 1.564 & 0.455 & 0.001 & 4.776 & 1.957 & 11.658 \\
\hline & $40-50$ & 0.628 & 0.336 & 0.061 & 1.874 & 0.971 & 3.618 \\
\hline & $50-60$ & 0.240 & 0.286 & 0.401 & 1.271 & 0.726 & 2.225 \\
\hline Children & 1 & 0.551 & 0.215 & 0.010 & 1.735 & 1.140 & 2.643 \\
\hline Violence & Yes & -0.701 & 0.228 & 0.002 & 0.496 & 0.318 & 0.775 \\
\hline \multicolumn{8}{|c|}{ Cervical screening of smear } \\
\hline \multirow{4}{*}{ Age } & $<30$ & -1.124 & 0.517 & 0.030 & 0.325 & 0.118 & 0.895 \\
\hline & $30-40$ & -0.021 & 0.468 & 0.964 & 0.979 & 0.391 & 2.450 \\
\hline & $40-50$ & 0.754 & 0.469 & 0.108 & 2.125 & 0.847 & 5.328 \\
\hline & $50-60$ & -0.010 & 0.371 & 0.979 & 0.990 & 0.479 & 2.049 \\
\hline Children & 1 & 0.597 & 0.294 & 0.042 & 1.816 & 1.021 & 3.231 \\
\hline \multicolumn{8}{|c|}{ Breast cancer screening } \\
\hline \multirow{4}{*}{ Age } & $<30$ & -1.576 & 0.486 & 0.001 & 0.207 & 0.080 & 0.536 \\
\hline & $30-40$ & -0.298 & 0.437 & 0.495 & 0.742 & 0.315 & 1.749 \\
\hline & $40-50$ & 0.201 & 0.418 & 0.631 & 1.223 & 0.539 & 2.777 \\
\hline & $50-60$ & 0.133 & 0.367 & 0.717 & 1.142 & 0.557 & 2.344 \\
\hline \multirow[t]{3}{*}{ Education } & Primary school & -1.137 & 0.430 & 0.008 & 0.321 & 0.138 & 0.745 \\
\hline & Middle school & -0.739 & 0.334 & 0.027 & 0.478 & 0.248 & 0.919 \\
\hline & High school & -0.305 & 0.346 & 0.378 & 0.737 & 0.374 & 1.452 \\
\hline Job & Yes & 0.576 & 0.237 & 0.015 & 1.779 & 1.118 & 2.831 \\
\hline \multicolumn{8}{|c|}{ Cesarean delivery } \\
\hline \multirow{4}{*}{ Age } & $<30$ & 2.777 & 0.492 & 0.000 & 16.069 & 6.125 & 42.154 \\
\hline & $30-40$ & 1.795 & 0.414 & 0.000 & 6.018 & 2.672 & 13.555 \\
\hline & $40-50$ & 0.493 & 0.417 & 0.238 & 1.636 & 0.723 & 3.706 \\
\hline & $50-60$ & 0.146 & 0.398 & 0.714 & 1.158 & 0.530 & 2.527 \\
\hline \multicolumn{8}{|c|}{ Induced abortion } \\
\hline \multirow{4}{*}{ Age } & $<30$ & -1.660 & 0.418 & 0.000 & 0.190 & 0.084 & 0.432 \\
\hline & $30-40$ & -0.468 & 0.266 & 0.079 & 0.626 & 0.371 & 1.055 \\
\hline & $40-50$ & -0.105 & 0.246 & 0.670 & 0.900 & 0.556 & 1.459 \\
\hline & $50-60$ & -0.123 & 0.223 & 0.581 & 0.884 & 0.572 & 1.369 \\
\hline Violence & Yes & 0.468 & 0.173 & 0.007 & 1.597 & 1.138 & 2.242 \\
\hline
\end{tabular}

aggression, malignant tumors, chronic lower respiratory diseases and road traffic accidents. Three of them were chronic diseases.

The common metabolic abnormalities are diabetes. Study showed overall diabetes prevalence was $8.1 \%$ and diabetes prevalence was associated with increasing age in New York City [4]. It was $22.4 \%$ among the residents 65 years and older. There was also an association between diabetes and infectious disease. Diabetes prevalence was significantly higher among women with tuberculosis and Hepatitis C virus-infection. Therefore, the health system and providers should recognize the associations between diabetes and infectious diseases and take effective preventable measures against diabetes among infected women.
A community-based cohort studies found 1461(10\%) participants had chronic kidney disease which would increase the risk of heart failure and coronary heart disease as 2.3 times comparing with participants without chronic kidney disease [5]. At the same time, Cardiovascular disease is the main cause of morbidity and mortality in patients with chronic kidney disease. Chronic disease caused functional disorder, affected the quality of life, and increased the burden of disease. But a variety of chronic disease can be prevented. Decreasing the risk factors, such as unhealthy diet, tobacco use, hypertension, hyperlipidemia, and physical inactivity, can improve the health of women, prevent the chronic disease to occur and economize the expense of medical resources. 
Reproductive health status is another issue affecting women health. The variables used to measure woman's reproductive health issues included prenatal examination, cervical scraping smear, breast check, cesarean delivery, and induced abortion in this study. Maternal morbidity and mortality can be decreased by prenatal examination. It also contributes to reduce the risk of cesarean delivery. The rate of cesarean delivery increased by years from $28.8 \%$ to $34.9 \%$ between 2008 and 2014 in China [6]. It was higher than the rate in this study. Sometimes cesarean delivery was not a necessary choice because it could increase some risk for child. For example, it was proved cesarean delivery was significantly associated with risk of autism spectrum disorder for each week of gestation, from week 36 to 42 compared with vaginal delivery [7]. Study results also showed there was no increase in maternal or perinatal mortality in 4 super cities with the largest decreases of cesarean delivery rate [6].

Breast and cervical screening is effective method to prevent gynecological tumors. It was proved that the positive rate of highrisk HPV in abnormal Pap smears was $53.8 \%$ in a developing nation [8]. Some preventive measures could be taken according to the Pap test in case of continued development. The mean percent women had a breast check and cervical scraping smear was $88.5 \%$ and $87.8 \%$ respectively in this study. It was especially higher among the women aged $40-50(92.9 \%)$ and $50-60(90.5 \%)$ years old in Beijing. The percentage of women screened among the 40-49 and 50-59 age groups were 58.5 and $62.5 \%$, respectively, between 2008 and 2009, and 56.9 and $62.0 \%$, respectively, between 2010 and 2011 in the united states [9]. The total proportion was $67 \%$ in American women older than 40 who had a mammogram in another study [10]. The proportion was lower in other areas. For example, only 57,340 (20\%) women had mammography screening among 286,785 registered women in mammography screening program in Latvia [11]. Women in Beijing were more aware of the prevention against breast cancer and cervical cancer compared with the other women.

Induced abortion is always a serious problem in reproduction health. The abortion rate was high in young women especially. Women aged $20-24$ and $25-29$ years accounted for $32.7 \%$ and $25.9 \%$ of all abortions, respectively in the united states [12]. The average abortion rate was high (38.5\%) in Beijing women. Abortion would cause physical harm but also lead to mental impairment, poor health, and productivity, or even death [13]. Improving psychological support for women experienced induced abortion involves listening them and respect their choice. Then increasing the access to and use of effective contraception can contribute to reduce unwanted pregnancies and further reduce the number of induced abortions.
The effective measures should be taken from two aspects in order to improve women health. One is for the health providers to explore new and innovative ways of designing and delivering health care services to meet woman's personalized service demands. The other is for health service recipients. Woman's awareness of health should be improved by empowering them and making themselves as drivers to change their health status.

\section{References}

1. Flavia Bustreo. The top issues for women's health. World Health Organization, 2015.

2. Gagnon AJ, Tuck J, Barkun L (2004) A systematic review of questionnaires measuring the health of resettling refugee women. Health Care Women Int; 25: 111-149. [Crossref]

3. Martinez JC (2016) Factors associated to mortality by non-communicable diseases in Colombia, 2008-2012. Biomedica 36: 535-546. [Crossref]

4. Drobnik A, Breskin A, Fuld J, Chan C, Hadler J, et al. (2016) Diabetes Among People with Tuberculosis, HIV Infection, Viral Hepatitis B and C, and STDs in New York City, 2006-2010. J Public Health Manag Pract 23: 461-467. [Crossref]

5. Bansal N, Katz R, Robinson-Cohen C, Odden MC, Dalrymple L, et al. (2016) Absolute Rates of Heart Failure, CoronaryHeart Disease, and Stroke in Chronic Kidney Disease: An Analysis of 3 Community-Based Cohort Studies. JAMA Cardiol 2: 314-318. [Crossref]

6. Li HT, Luo S, Trasande L, Hellerstein S, Kang C, et al. (2017) Geographic Variations and Temporal Trends in Cesarean Delivery Rates in China, 2008-2014. JAMA 317: 69-76. [Crossref]

7. Yip BH, Leonard H, Stock S, Stoltenberg C, Francis RW,et al. Caesarean section and risk of autism across gestational age: a multi-national cohort study of 5 million births. Int J Epidemiol 46: 429-439. [Crossref]

8. Othman N, Othman NH (2014) Detection of human papillomavirus DNA in routine cervical scraping samples: use for a national cervicalcancer screening program in a developing nation. Asian Pac J Cancer Prev 15: 2245-2249. [Crossref]

9. Qin X, Tangka FK, Guy GP, Howard DH (2016) Mammography rates after the 2009 revision to the United States Preventive Services Task Force breast cancer screening recommendation. Cancer Causes Control 28: 41-48.

10. Barnes DM, Harrison CL (2004) Refugee women's reproductive health in early resettlement. J Obstet Gynecol Neonatal Nurs 33: 723-728. [Crossref]

11. Hegmane A, Eglitis J (2011) Population-based mammography screening program in Latvia: Results of the first round. J Clin Oncol 29 (15_suppl): e11038.

12. Jatlaoui TC, Ewing A, Mandel MG, Simmons KB, Suchdev DB, et al. (2016) Abortion Surveillance - United States, 2013. MMWR Surveill Summ 65: 1-44. [Crossref]

13. Heikinheimo O, Pohjoranta E, Toffol E (2016) Reply on 'Anxiety and quality of life after first-trimester termination of pregnancy: a prospective study'. Acta Obstet Gynecol Scand.

Copyright: (C2017 Wang X. This is an open-access article distributed under the terms of the Creative Commons Attribution License, which permits unrestricted use, distribution, and reproduction in any medium, provided the original author and source are credited. 